Check for updates

Cite this: RSC Adv., 2017, 7, 38135

\title{
A new understanding of the failure of waterborne acrylic coatings
}

\author{
Hongxia Wan, ${ }^{a}$ Dongdong Song, (D) *b Xiaogang Li, ${ }^{\text {ac }}$ Dawei Zhang, ${ }^{a}$ Jin Gao $^{a}$ \\ and Cuiwei $\mathrm{Du}^{\mathrm{a}}$
}

In this study, two types of waterborne acrylic coatings, including a styrene-acrylic coating and a terpolymer coating based on acrylic acid, vinyl chloride and 1,1-dichloroethylene segments, were compared in terms of their barrier properties and wet adhesion after being immersed in $3.5 \mathrm{wt} \% \mathrm{NaCl}$ solution. Both coatings with and without artificial defects showed completely different corrosion protection performance when immersed in 3.5 wt\% $\mathrm{NaCl}$ solution. Meanwhile, electrochemical impedance spectroscopy (EIS) was also used to investigate the corresponding coatings' failure process. The results of these tests expound that the barrier property played the dominant role for the corrosion protection of the intact coatings, while the wet adhesion is the decisive factor when a large defect exists in the coating surface. The effect of wet adhesion in corrosion protection was further investigated through the thinner intact coatings. The combination of barrier property and wet adhesion is crucial for coatings to sustain long-term corrosion protection.

Received 1st May 2017

Accepted 23rd July 2017

DOI: $10.1039 / \mathrm{c} 7 \mathrm{ra0} 4878 \mathrm{e}$

rsc.li/rsc-advances surfaces. Presence of the corrosive medium at the coating/metal interface can destroy the electrostatic interactions between the coating and metal, and consequently, weaken the coating adhesion and promote metallic corrosion under the film. Therefore, the adhesive force of the coating/metal interface, particularly the wet adhesive force, ${ }^{\mathbf{1 0 , 1 1}}$ which can significantly hinder the lateral diffusion of the corrosive ions in the coating/ metal interface, is considered as the most important factor for determining the protection properties of the coatings for a metal substrate. In general, for organic coatings applied to a metal substrate, the most common type of adhesion is via secondary and chemical bonds. ${ }^{\mathbf{1 2 - 1 4}}$ The former (weak noncovalent bond include hydrogen bonds and van der Waals interactions) widely exist at the coating/metal interface and result in weak bonding, which is easily broken by the corrosive medium. In comparison, the chemical bonds (such as strong non-covalent bond include ionic bond and covalent bonds) formed at the coating/metal interface through the interactions between the polar groups of the coating and the metal substrates, can offer a much stronger adhesion. Yamabe ${ }^{15}$ investigated the interface between poly acrylic acid and various types of metal substrates, and confirmed that a strong ionic interaction between the carboxyl group and metal existed. Sørensen ${ }^{\mathbf{1 6}}$ reported that the adhesive force in the coating/metal interface was enhanced with increasing number of carboxyl groups in the coating. In addition, Friedrich ${ }^{\mathbf{1 7}}$ studied the adhesive ability of different polar groups applied on an aluminum substrate, and obtained the following order of adhesive ability of the different functional groups: $\mathrm{COOH}>\mathrm{OH}$ $\gg \mathrm{NH}_{2}>\mathrm{CH}_{2}$. From these studies, we understand that the anstitute for Advanced Materials and Technology, University of Science and Technology Beijing, Beijing 100083, P. R. China. E-mail: lixiaogang99@263.net; Fax: +86-10-62334005; Tel: +86-10-62333931 ext. 509

${ }^{b}$ Aerospace Research Institute of Materials and Processing Technology, Beijing, 100076, P. R. China. E-mail: sddtheone@126.com; Fax: +86-10-62334005; Tel: +86-1062333931 ext. 502

${ }^{c}$ Ningbo Institute of Material Technology and Engineering, Chinese Academy of Sciences, Ningbo 315201, Zhejiang, P. R. China 
carboxyl groups present in the coating can form stable bonds with metal substrates. Currently, most research ${ }^{18-21}$ still focuses on the relationship between the structure and barrier property of waterborne coatings to improve their anticorrosion performance. The loss of adhesion at the coating/metal interface during practical engineering applications limits the long-term stability of waterborne coatings. However, a systematic study of the barrier performance and adhesion of waterborne coatings in a corrosive environment is relatively rare.

In this work, we evaluated the corrosion performance of waterborne acrylic coatings in terms of their barrier property and wet adhesion. These properties were first investigated via a combination of immersion and electrochemical impedance spectroscopy (EIS) tests conducted for both intact and defective coatings. The barrier property of each coating was investigated via physical and electrochemical methods, and two types of waterborne acrylic coatings with an average thickness of $85 \mu \mathrm{m}$ were used for the immersion tests. The adhesion property of the coatings was studied by examining coatings with linear shaped artificial defects under the same conditions. This property was also verified via thinner coatings of $20 \mu \mathrm{m}$ thickness. The relationship between the disbonding process and anticorrosion ability of the coatings was clearly explained with the complementary results of the immersion tests.

\section{Experiment}

\subsection{Materials}

In this study, we use two waterborne coatings, namely, a styrene-acrylic coating and a terpolymer coating consisting of acrylic acid $\left(\mathrm{CH}_{2}=\mathrm{CH}-\mathrm{COOH}\right)$, vinyl chloride $\left(\mathrm{CHCl}=\mathrm{CH}_{2}\right)$, and 1,1-dichloroethylene $\left(\mathrm{CH}_{2}=\mathrm{CCl}_{2}\right)$.

\subsection{Sample preparation}

Q235 carbon steel was used as the metal substrate, and was first polished by a 240-grit abrasive paper to remove the surface oxide layer. After polishing, the metal surface was carefully washed in ethanol and acetone, and then dried prior to the coating process. The water-based acrylic acid coating was painted on the metallic surface by a brush, and cured at room temperature for 15 days. The thicknesses of the dry film were controlled to be 85 and $20 \mu \mathrm{m}$, respectively. The measure device (QNix4500 0-50 $\mu \mathrm{m} \leq \pm 1 \mu \mathrm{m}$ ) was used to control the thicknesses of the dry film. And both of the two coatings have good liquidity and leveling. A linear-shaped artificial defect (width $50 \mu \mathrm{m}$, length $\sim 1 \mathrm{~cm}$ ) was generated in a portion of the surface coatings (thickness $\sim 85 \mu \mathrm{m}$ ).

\subsection{Characterization of the coating}

The surface morphologies of the two coatings during the immersion tests were monitored using a digital camera (Nikon D7000) and digital microscope VHX-2000 (Keyence, Japan).

The Data Physics contact angle measurement system (OCA20) was used to measure the contact angle of different coating surfaces, and the volume of water was approximately 5 $\mu \mathrm{L}$.
Differential scanning calorimetry (DSC) measurements were performed under $\mathrm{N}_{2}$ gas using DSC Q2000 (TA Instruments) at a heating rate of $10{ }^{\circ} \mathrm{C} \mathrm{min}^{-1}$. The glass transition temperature $\left(T_{\mathrm{g}}\right)$ of the epoxy was determined as the inflection temperature, while the $T_{\mathrm{m}}$ value was obtained from the endothermic peak in the DSC curve.

The $\mathrm{pH}$ values of the coating latex were measured by a Thermo Orion Star A321 Portable pH Meter.

To investigate the physical structure of these coatings, AFM measurements were performed for the coating samples using the smart mode of a MultiMode ${ }^{\mathrm{TM}}$ Nanoscope V.

\subsection{Immersion test}

The coatings (thickness $\sim 85 \mu \mathrm{m}$ ) with and without the defects were immersed in $3.5 \mathrm{wt} \% \mathrm{NaCl}$ solution, and for the intact thinner coatings (thickness $\sim 20 \mu \mathrm{m}$ ) the same immersion tests were performed. The changes in the morphologies of the samples during the immersion process were carefully recorded.

\subsection{Wet adhesion test}

The sample size was $50 \times 150 \mathrm{~mm}$ and the thickness of the coating was $85 \mu \mathrm{m}$. An art knife was used to produce a $20 \mathrm{~mm}$ wide defect in the center of the sample. It was ensured that the metal substrates were exposed to air. Next, the samples were placed in the $3.5 \mathrm{wt} \% \mathrm{NaCl}$ solution $(\mathrm{pH}=7)$ under $30^{\circ} \mathrm{C}$. After the immersion, the samples were taken out and placed in an environment of $50 \%$ humidity and $25{ }^{\circ} \mathrm{C}$ for $2 \mathrm{~h}$. After this, a piller was stuck on the sample surface, and the distance between the center of piller and defect was kept at $25 \mathrm{~mm}$. Before the test, the sample was placed in an environment for $24 \mathrm{~h}$ for the piller and sample to get tightly bound. The wet adhesion test was performed by the PosiTest AT Pull-Off Adhesion Tester (America, DeFelsko). The diameter of the piller was $20 \mathrm{~mm}$.

\subsection{Electrochemical test}

The EIS measurements were performed in a $3.5 \mathrm{wt} \% \mathrm{NaCl}$ solution using the PARSTAT 2273 electrochemical station in a frequency range of $10^{5} \mathrm{~Hz}$ to $10^{-2} \mathrm{~Hz}$. A conventional three electrode cell was used, with a $3.14 \mathrm{~cm}^{2}$ area of the sample as the working electrode, platinum plate as the counter electrode, and a saturated calomel electrode (SCE) as the reference electrode. Impedance data were evaluated at an open circuit potential (OCP) by applying $20 \mathrm{mV}$ sinusoidal perturbations (rms signal). The electrochemical cell was placed in a Faraday cage to avoid external electromagnetic fields and stray currents interferences.

LEIS measurements were performed on the coating specimens that were immersed in the $3.5 \mathrm{wt} \% \mathrm{NaCl}$ solution via a PAR Model 370 Scanning Electrochemical Workstation. The test solution for the LEIS measurements was $0.001 \mathrm{M} \mathrm{NaCl}$ solution. The microprobe was stepped over a designated area of the electrode surface. The scanning took the form of a raster in the $x-y$ plane. The step size was controlled to obtain a plot of 32 $\times 21$ lines. The AC disturbance signal was $100 \mathrm{mV}$, and the excitation frequency for the impedance measurements was 
fixed at $5 \mathrm{kHz}$. All LEIS measurements were conducted at ambient temperature $\left(\sim 22^{\circ} \mathrm{C}\right)$. Each test was performed at least three times to confirm repeatability.

\subsection{FTIR analysis}

FTIR spectra were recorded on a PerkinElmer Frontier spectrometer. The spectra of chemical changes in coatings was used in the range of 4000-650 $\mathrm{cm}^{-1}$ with 16 scans and a resolution of $4 \mathrm{~cm}^{-1}$. Changes between resin and coating were tested to study the bond between coating and metal. The samples were prepared by the spreader (OSP-04) and the thicknesses of the dry film were less than $2 \mu \mathrm{m}$.

\subsection{SIMS}

An ION-TOF GmbH TOF-SIMS 5 TOF ion mass spectrometry system was used to analyze the chemical composition of the coating/metal interface.

\section{Results}

\subsection{Properties of the coatings}

The corrosion protection provided by a coating is always related to several factors such as the hydrophobicity of the coating surface, crosslinking reaction, and $T_{\mathrm{g}}$ of the coating resin. ${ }^{22}$ Some major parameters of the both the coatings are shown in Table 1.

Hydrophobicity of both coating surfaces was tested via contact angle measurements. The results (Table 1) show that the contact angles of the styrene-acrylic coating is $76.0 \pm 1.6^{\circ}$, which implies the coating surface can repel water or other liquids to a certain degree. The terpolymer coating has a smaller contact angle of $50.0 \pm 0.2^{\circ}$, indicating its hydrophilicity and easiness to absorb water compared to the styrene-acrylic coating. The presence of benzene rings, which favors the hydrophobic property of the coating resin, will increase the contact angle of the styrene-acrylic and increase its hydrophobicity. ${ }^{23}$

In addition, the $T_{\mathrm{g}}$ values of the two coatings are also shown in Table 1, and we deduce that the $T_{\mathrm{g}}$ of the styrene-acrylic coating is $25{ }^{\circ} \mathrm{C}$, which is higher than the $T_{\mathrm{g}}\left(10^{\circ} \mathrm{C}\right)$ of the terpolymer coating. It is known that the $T_{\mathrm{g}}$ affects the hardness of the coating. A high $T_{\mathrm{g}}$ value of the coating favors its mechanical properties, and allows sufficient chain inter diffusion, which results in densely packed latex nanoparticles of coating. ${ }^{24}$ When the polymer diffusion was not sufficient, the mechanical properties of the coating were weakened as the polymer chains were not locked. These soft polymer chains allow easy penetration of water and other corrosive ions through the film, and consequently, react with the metallic

Table 1 Parameters of the two coatings

\begin{tabular}{llll}
\hline Coating & Contact angle & $T_{\mathrm{g}}{ }^{\circ} \mathrm{C}$ & $\mathrm{pH}$ \\
\hline Styrene-acrylic coating & $76.0 \pm 1.6^{\circ}$ & 25 & $7-7.5$ \\
Terpolymer coating & $50.0 \pm 0.2^{\circ}$ & 10 & $1-2$
\end{tabular}

substrate. $^{25}$ A low hydrophobicity and $T_{\mathrm{g}}$ value for the terpolymer coating will deteriorate the water-resistance, and will primarily lead to faster degradation of the terpolymer coating on exposure to water and the $\mathrm{NaCl}$ solution compared to the styrene-acrylic coating.

The $\mathrm{pH}$ values of the latex of both the coatings can also be obtained from Table 1 . The $\mathrm{pH}$ value of the styrene-acrylic coating is approximately 7-7.5, i.e., it is neutral. In comparison, the latex of the terpolymer coating is acidic with a $\mathrm{pH}$ value of approximately 1-2. Although both the coatings contain acrylic molecules, they exhibited totally different acid-alkali properties. This may be attributed to the ionization of majority of the carboxylic acids in the latex of the terpolymer coating that enhances the acid degree of the latex. In comparison, the styrene-acrylic coating has few ionized carboxylic acids, so that its latex remains neutral.

Fig. 1a reveals the nanostructure of the styrene-acrylic coating consists of uniform particles $c a .100 \mathrm{~nm}$ in size that are closely packed with a compact structure. The surface is very smooth even at the nanometer scale. This observation indicates that during the film formation process, the particles came into close contact with each other and then deformed to fill the void spaces between them to generate a very smooth surface. This is in agreement with the observations for a proper film formation from a latex system. It has been reported that uniform spherical latex particles, $c a$. $100 \mathrm{~nm}$ in size, were closely packed in the coating, whereas some small voids were seen at the particle boundaries. ${ }^{26-29}$ Fig. 1b shows the AFM image of the terpolymer coating, similar to that of the styrene-acrylic coating, but discloses a larger size and higher roughness.

\subsection{Wet adhesion testing}

To evaluate the wet adhesive force of intact and defective the coatings, a series of wet adhesion tests were performed in different immersion times. The morphologies of the fracture coating surface after the completion of pull-off tests are shown in Fig. 2. Fig. 2a shows that the fracture mode of intact styreneacrylic coating is a mixed form of the bulk cohesive fracture and a broken adhesive layer and remains unchanged. For intact terpolymer coating, only bulk cohesive fracture is observed. But after immersion of 80 day, the fracture mode is changed to mixed form of the bulk cohesive fracture and broken on the surface between coating and metal. For defective coating (Fig. 2b), the fracture mode of the styrene-acrylic coating is a mixed form of the bulk cohesive fracture and a broken adhesive layer; however, for the terpolymer coating, only bulk cohesive fracture is observed. With increase in the immersion time, the fracture mode of the styrene-acrylic coating turns into the cracking of the coating/metal interface, while that of the terpolymer coating remains unchanged. After 8 days of immersion, evident underfilm corrosion can be seen in the morphology of the fracture coating surface for the styrene-acrylic coating, while the terpolymer coating maintains a good adhesion state.

Fig. 3a shows the wet adhesive force of intact coating corresponding to the wet adhesion tests under different test cycles. The initial adhesive force of the styrene-acrylic coating is 

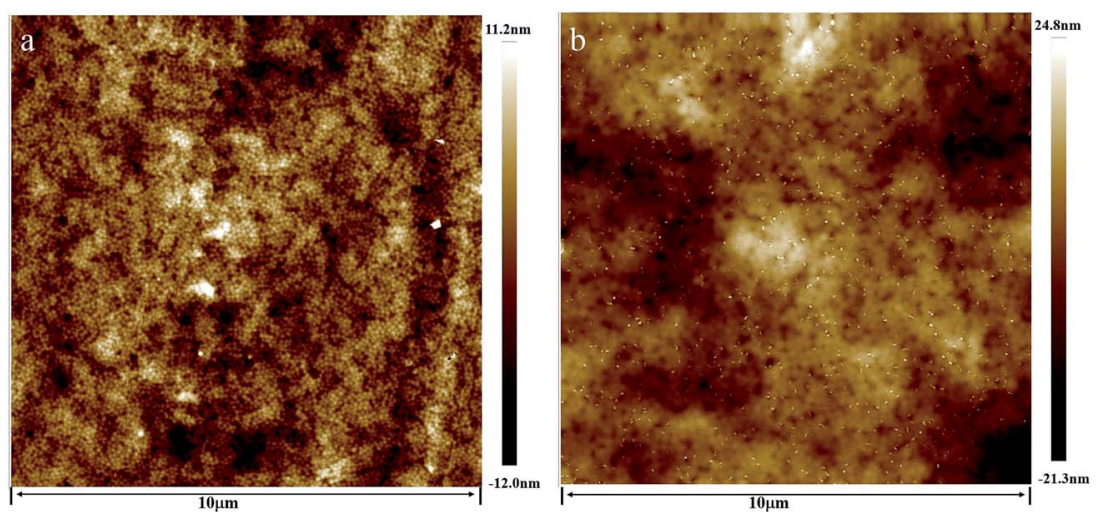

Fig. 1 AFM topography images of the two coatings, (a) styrene-acrylic coating; (b) terpolymer coating.

approximately $5 \mathrm{MPa}$, which is almost twice that of the terpolymer coating $(2.75 \mathrm{MPa})$. This can be attributed to the difference in the failure modes. The terpolymer coating is extremely soft to withstand the pulling force. ${ }^{30,31}$ Both of coatings keep little change during the immersion time.

Fig. 3b shows the wet adhesive force of defective coating corresponding to the wet adhesion tests under different test cycles. However, as the immersion time increases, the adhesive force of the styrene-acrylic coating rapidly decreases, and its value after 8 days of immersion is only $20 \%$ of the initial force. In contrast, the terpolymer coating always maintains the same state as at the beginning. These results reveal that the terpolymer coating has a more reliable bonding at the coating/ metal interface compared to the styrene-acrylic coating in the presence of defects. This can be attributed to the good wet adhesive force that can effectively suppress the lateral diffusion of the corrosive ions to the coating/metal interface.

\subsection{Immersion test for the coatings with $85 \mu \mathrm{m}$ thickness}

The barrier properties of the two coatings were first evaluated via immersion tests. In these tests, a thick coating was used to

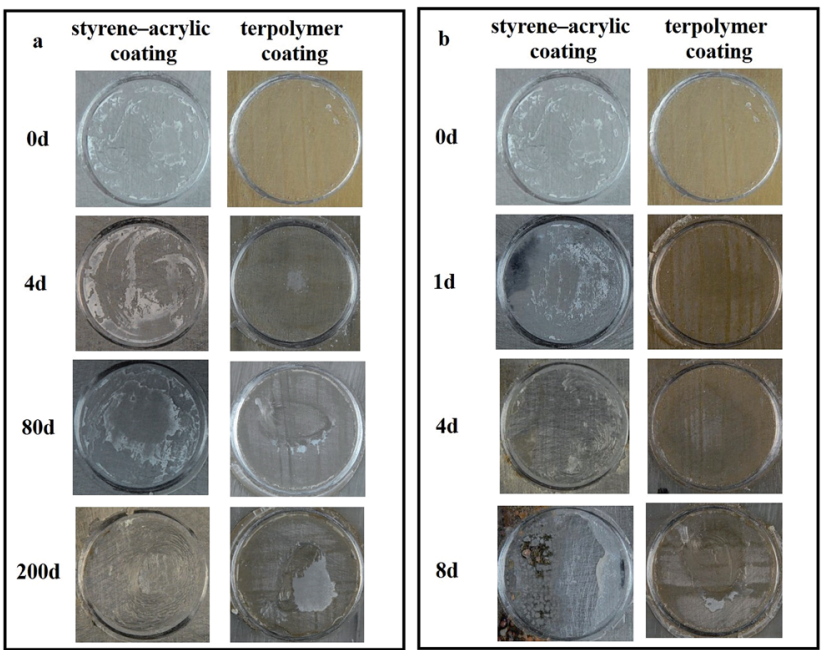

Fig. 2 Morphologies of (a) the intact coatings and (b) the defective coating after the pull-off tests at different immersion times. cover the micro defects generated during the film forming process. Fig. 4 shows the morphological changes of the two coatings (thickness $85 \mu \mathrm{m}$ ) immersed in the $3.5 \mathrm{wt} \% \mathrm{NaCl}$ solution as a function of immersion time. The images demonstrate that both the coatings have favorable barrier properties, and no severe corrosion is observed in their morphologies even after 300 days of immersion. Comparing the morphological changes of the two coatings, the styrene-acrylic coating exhibits a better anticorrosion property. There are no apparent changes in the coating surface after immersion of 300 days, and the
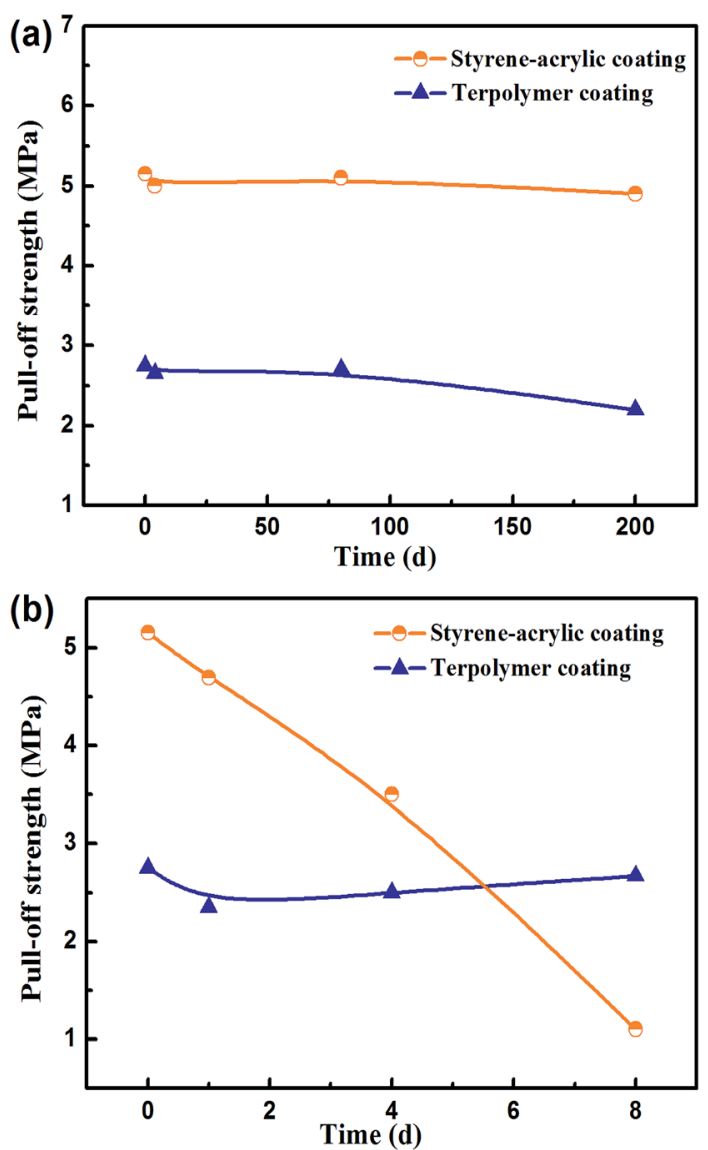

Fig. 3 Wet adhesive force of (a) intact coating and (b) defective coating as a function of immersion time. 


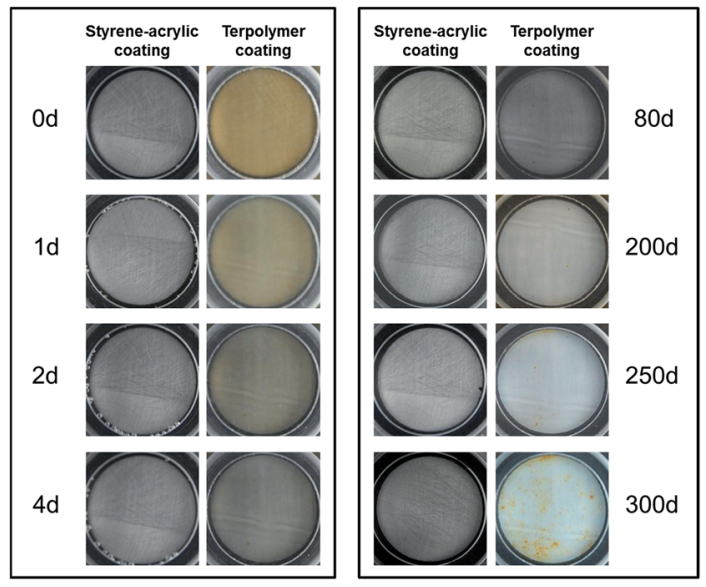

Fig. 4 Morphologies of the coatings with $85 \mu \mathrm{m}$ thickness immersed in $3.5 \mathrm{wt} \% \mathrm{NaCl}$ solution during different test cycles.

coating surface is still smooth and has integrity. In contrast, the terpolymer coating exhibits a relatively poor barrier performance as depicted by the change in the color of the coating surface from golden yellow to white because of water absorption after 4 days of immersion. The coating surface appears to have a rust spot when immersed for 200 days, which gradually increase along with the extension of the immersion time.

\subsection{Electrochemical behavior of the coatings with $85 \mu \mathrm{m}$ thickness}

To better understand the degradation process of both the coatings, which cannot be visualized, electrochemical tests were performed. Fig. 5 displays the results of the electrochemical tests of both the coatings immersed in $3.5 \mathrm{wt} \% \mathrm{NaCl}$ solution. Fig. $5 \mathrm{a}$ and $\mathrm{b}$ are the Bode and Nyquist plots of the EIS spectra, respectively for the styrene-acrylic coating. A low-frequency impedance $\left(|Z|_{0.01 \mathrm{~Hz}}\right)$ is always maintained above $10^{10} \Omega$ within 250 days of the immersion test, and in the corresponding Nyquist plot, the coating behaves as a capacitance arc in the whole entire immersion test. These results show that the styrene-acrylic coating continues to absorb water even after 300 days of immersion.

For the terpolymer coating, the immersed coating undergoes three immersion stages as observed from the Bode (Fig. 5c) and Nyquist plots (Fig. 5d) of the EIS spectra. Before 110 days, the immersed coating stays in the first stage, which is similar to the
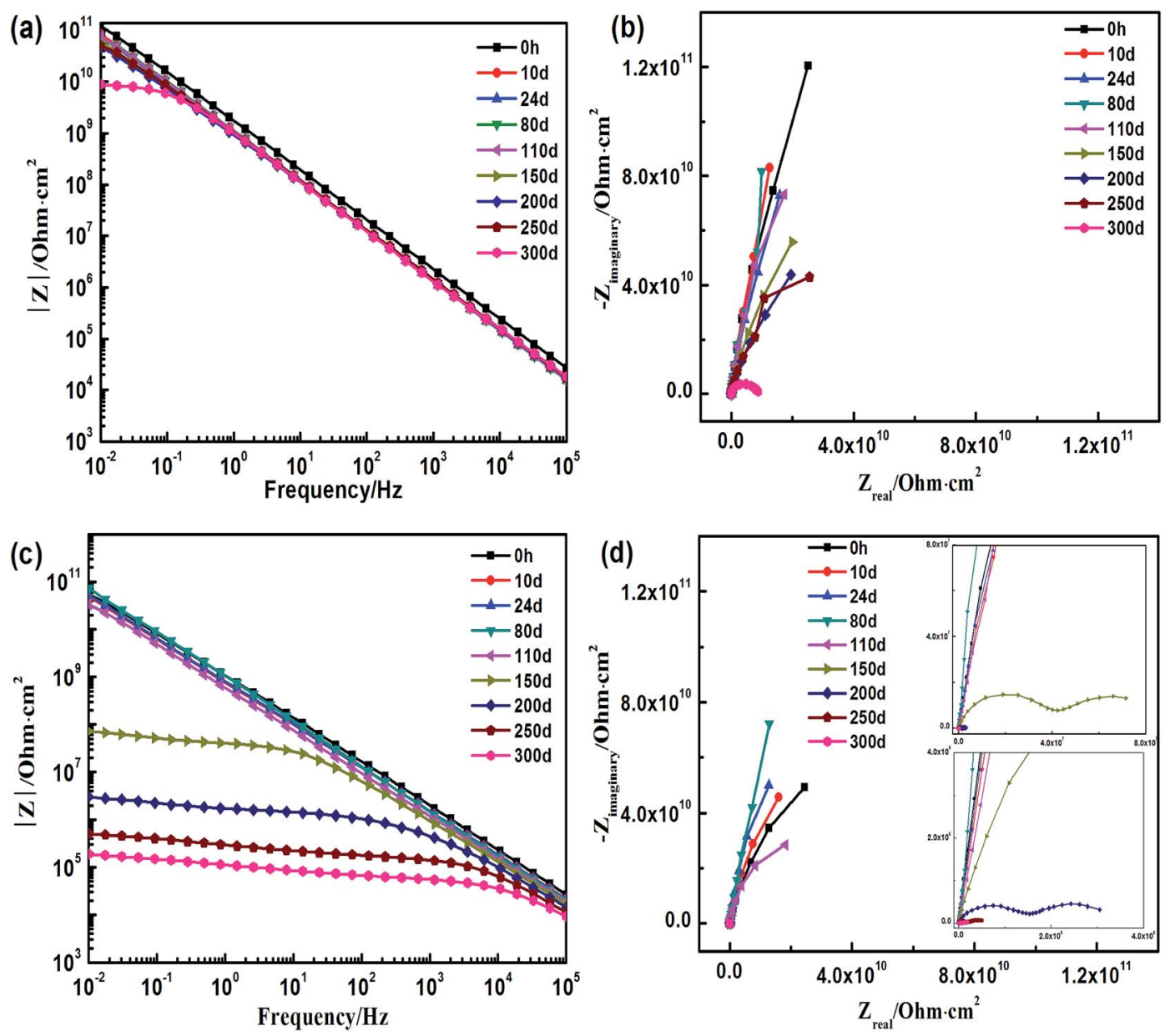

Fig. 5 Electrochemical impedance of the coatings with $85 \mu \mathrm{m}$ thickness at different immersion times (a) and (b) Bode and Nyquist plots of the styrene-acrylic coating, (c) and (d) Bode and Nyquist plots of the terpolymer coating. 
styrene-acrylic coating, such that a low-frequency impedance is found above $10^{10} \Omega$ and the coating impedance acts as a capacitance arc. The coating gradually deteriorates around 150 days of immersion with the low-frequency impedance decreasing to $10^{7} \Omega$ and the coating impedance appearing as two squashed capacitance arcs. After 250 days of immersion, the coating loses its barrier property and the low-frequency impedance is found below $10^{6} \Omega$.

Because the styrene-acrylic coating retained its excellent barrier property at most immersion times, the circuit model as shown in Fig. 6a was used to fit its impedance. In comparison, the impedance of the terpolymer coating is fitted by a one-time constant circuit model up to 150 days of immersion. After this the metal substrate under the coating corrodes and two time constant circuit models shown in Fig. $6 \mathrm{~b}$ are used to match later the immersion stage of the terpolymer coating. In the circuits, $R_{\mathrm{s}}$ represents the resistance between the working electrode and reference electrode. It is generally associated with the ohmic resistance of the electrolyte. $Q_{\mathrm{dl}}$ and $R_{\mathrm{ct}}$ are related to the doublelayer capacitance and charge-transfer resistance of the chemically active pigments, respectively. $Q_{\mathrm{c}}$ is related to the capacitance of the coating. $R_{\mathrm{c}}$ is the resistance of the pores and is a measure of the porosity as a consequence of the degradation of the coating.

Fig. 7 displays the variation of the capacitances of the two coatings in $3.5 \mathrm{wt} \% \mathrm{NaCl}$ solution as a function of the immersion time. It can be observed from the variation trend for the styrene-acrylic coating that its immersion process consists of two stages. In the initial stage (0-10 days), the capacitance of the coating increases rapidly, which indicates that water and other corrosive ions move along the microporous structure of the coating and quickly penetrate through the coating. After 10 days of immersion, the curve exhibits a plateau and the capacitance of the coating becomes stable. This indicates that water absorption of the coating becomes saturated. As for the terpolymer coating, the capacitance of the coating begins to rapidly increase after 80 days of immersion. This suggests that the coating gradually loses its barrier property. This phenomenon did not appear for the styrene-acrylic coating in the entire immersion test (i.e., 300 days).
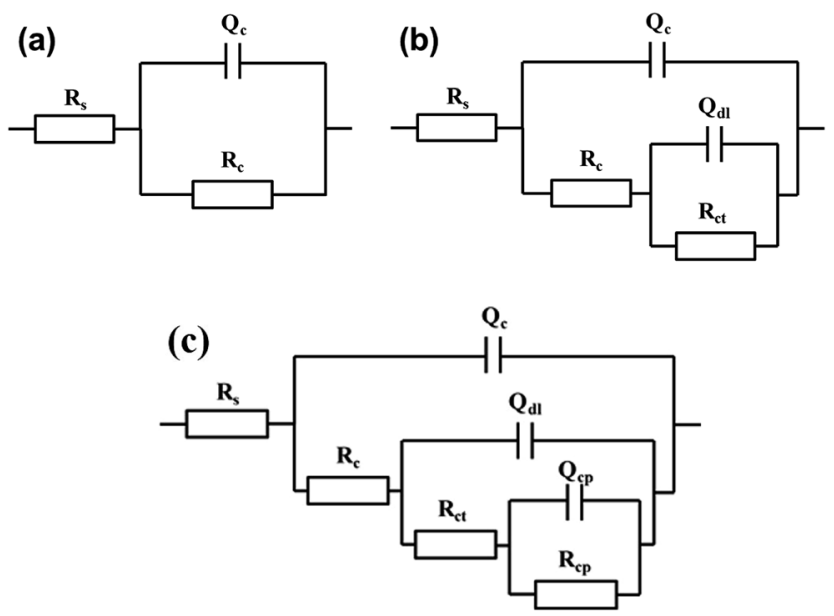

Fig. 6 Circuit models for fitting the impedance of the coatings.

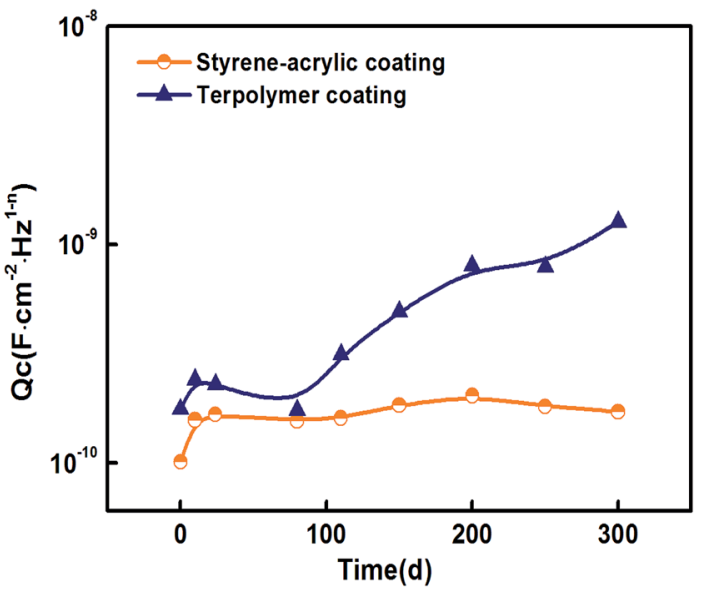

Fig. $7 Q_{c}$ versus $t$ variations for the two coatings.

\subsection{Immersion test for the coatings with $20 \mu \mathrm{m}$ thickness}

To further verify the role of wet adhesion in the corrosion protection from another aspect, thinner coatings were used to conduct the immersion tests. When the coating is very thin, existence of micro defects in the coating is inevitable, and the coating/metal interface will be easily exposed to the electrolyte solution and susceptible to the occurrence of corrosion reactions. Under this condition, the bonding between the coating and metal plays a major role in protecting the metal substrates. To assess the bonding effect in the two coatings, the coating thickness is controlled to approximately $20 \mu \mathrm{m}$. Fig. 8 shows the morphological changes of the two coatings immersed in 3.5 $\mathrm{wt} \% \mathrm{NaCl}$ solution at different immersion times. Fig. 8 displays the protective ability of the styrene-acrylic coating rapidly decreases as the thickness reduces. After 12 hours of immersion, the coating surface has undergone obvious corrosion. The corrosion develops rapidly with time, and the corrosion area of the coating surface is more than $50 \%$ after 2 days of immersion. For the terpolymer coating under the same condition, although rust spots appear on the coating surface after immersion of $12 \mathrm{~h}$, the rust spots develop slowly and no large area of the blister is formed in the subsequent immersion tests. This shows

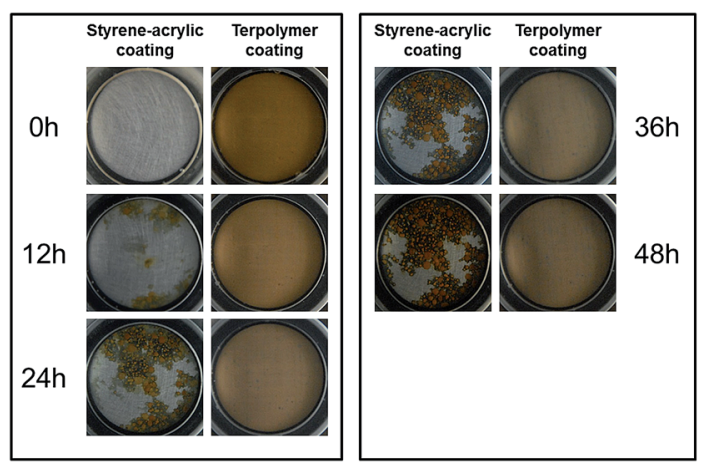

Fig. 8 Morphologies of the two coatings with $20 \mu \mathrm{m}$ thickness immersed in $3.5 \mathrm{wt} \% \mathrm{NaCl}$ solution at different immersion times. 
that terpolymer coating exhibits better corrosion resistance than the styrene-acrylic coating.

In addition, the corrosion forms of the two coatings were different. For the styrene-acrylic coating, the corrosion takes place with blisters and most of the blisters are connected with each other after immersion of 2 days itself. For the terpolymer coating, just happened the underfilm corrosion without blister, but these areas are separated respectively.

When the coating is very thin, the barrier property will be lost because of the micro generation of defects during the film forming process. Simultaneously, the wet adhesion force in the coating/metal interface will be the dominating factor for delaying the corrosion reactions. Underfilm corrosion takes place at both the coatings in a very short time because of the loss of barrier property. However, for the styrene-acrylic coating, severe corrosion occurred. The corrosion areas are connected with each other owing to the low level of the wet adhesive force for the styrene-acrylic coating, which cannot hinder the transverse diffusion of the corrosive ions in the coating/metal interface. The terpolymer coating has the better wet adhesive force, which can effectively reduce the rate of diffusion of corrosive ions, and leads to the separation of the corrosion areas.

\subsection{Electrochemical behavior of the coatings with $20 \mu \mathrm{m}$ thickness}

The corresponding electrochemical tests were also performed in the same time, and the EIS results showed in the Fig. 9. The styrene-acrylic coating is rapidly destroyed under the condition of low thickness, as shown in Fig. 9a and b. The impedance magnitude at the low frequency was under $10^{5} \Omega$ even after completion of $12 \mathrm{~h}$, and this was shifted to $10^{3} \Omega$ merely after one day, which indicates that the styrene-acrylic coating has entirely lost its barrier property. In contrast, low-frequency of the terpolymer coating is always maintained above the $10^{6} \Omega$ after 10 days of immersion (Fig. 9c and d).

For the coatings with $20 \mu \mathrm{m}$ thickness, because the corrosive ions quickly infiltrate into the coating and corrosion reactions occur in the coating/metal interface, the impedance behaves as two time constants in the initial immersion test for the styreneacrylic coating. Therefore, the circuit model in Fig. $6 \mathrm{~b}$ can fit the impedance of the styrene-acrylic coating. For the terpolymer coating, the two time constants appeared in the early stage of the immersion; however, due to its high level of wet adhesive force, the corrosion only takes place in a relatively small area and is suppressed. Therefore, the circuit model on Fig. 6c is used to do the fitting analysis for the terpolymer coating. $Q_{\mathrm{cp}}$
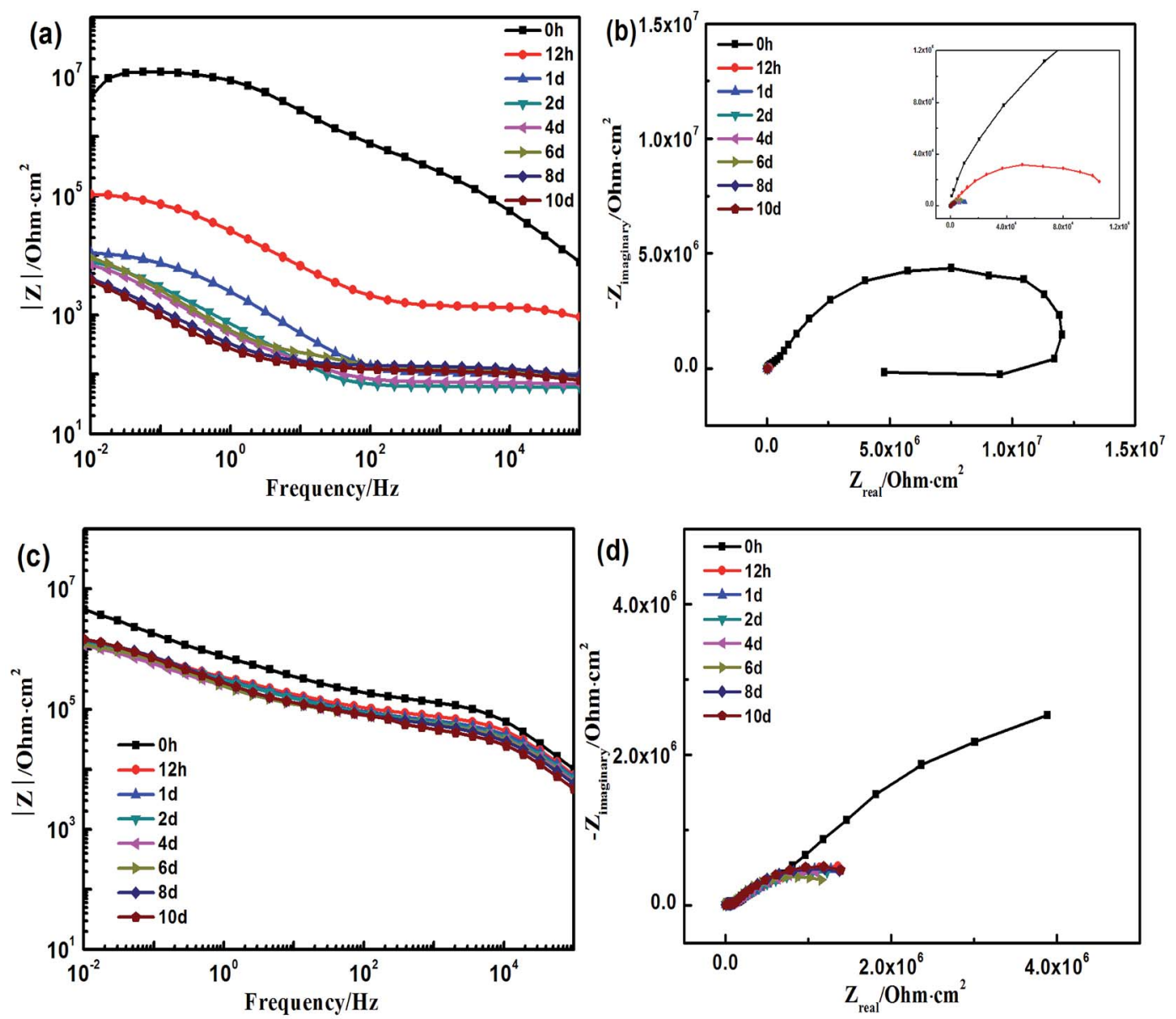

Fig. 9 The electrochemical impedance of the coatings with $20 \mu \mathrm{m}$ thickness in the different immersion time (a) and (b) Bode and Nyquist plots of the styrene-acrylic coating, (c) and (d) Bode and Nyquist plots of the terpolymer coating. 


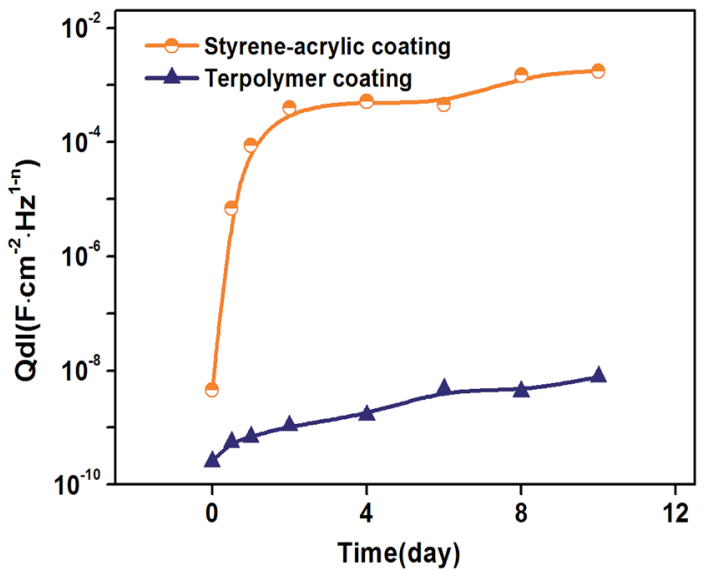

Fig. 10 The double-layer capacitance, $Q_{\mathrm{dl}}$, as a function of the immersion time of the coatings with $20 \mu \mathrm{m}$ thickness in the different immersion time.

and $R_{\mathrm{cp}}$ are related to the stacking of corrosion product. Fig. 10 displays the $Q_{\mathrm{dl}}$ versus $t$ curves derived for the circuit fitting. The $Q_{\mathrm{dl}}$ values of the styrene-acrylic coating are much higher than that of the terpolymer coating, which reveals that the terpolymer coating has a better ability to resist the coating/ metal interface corrosion in comparison with the styreneacrylic coating.

\subsection{Immersion test for the defective coatings with $85 \mu \mathrm{m}$ thickness}

In an intact coating, the barrier property is the main factor that ensures the corrosion protection. However, when a large defect appears in the coating surface, the corrosive species can directly attack the metal surface; furthermore, the corrosion protection mainly relies on the wet adhesive force. Strength bonding in the coating/metal interface not only effectively prevents the external electrolyte solution infiltration into the matrix and delay of the interface corrosion cell formation, but can also strongly hinder the diffusion of the dissolved metallic cation through the cathodic region, which in turn reduces the flow of the anodic and cathodic currents on the metal surface.

Fig. 11 displays the two types of scratched coatings of $85 \mu \mathrm{m}$ thickness immersed in $3.5 \mathrm{wt} \% \mathrm{NaCl}$ solution at different immersion times. In contrast to the results for the intact coatings, the styrene-acrylic defective coating shows a weaker corrosion protection performance when a large defect exists in the coating surface compared with the terpolymer coating. Significant rust is found around the defect of the styrene-acrylic coating simply 1 day after the immersion, and corrosion products accumulate with the extension of time. In contrast, there is no evident degradation of the defective terpolymer coating, and the rust around the defect develops slowly.

From the three-dimensional (3D) morphology (Fig. 12) of the two scratched coatings, the degree of degradation for two coatings can be more clearly observed. The styrene-acrylic coating is severely peeled off and corrosion products accumulate around the defect area (Fig. 12a). Only a little rust is

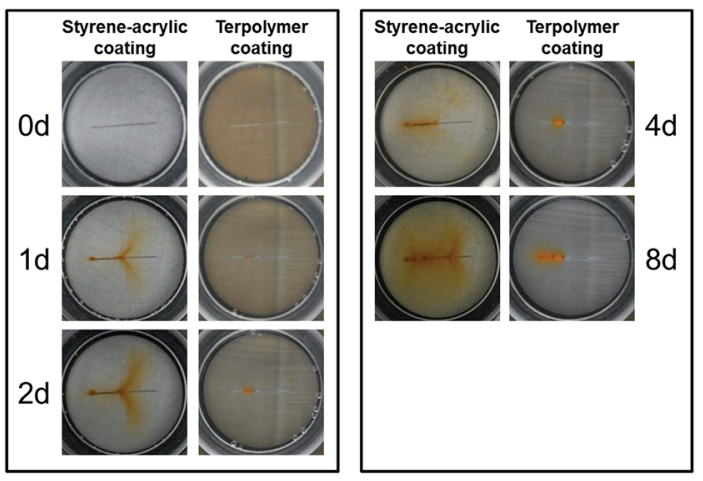

Fig. 11 Morphologies of the two defected coatings with $85 \mu \mathrm{m}$ thickness immersed in $3.5 \mathrm{wt} \% \mathrm{NaCl}$ solution during different test cycles.

produced in the defect area of the terpolymer coating without a blister (Fig. 12b).

\subsection{Electrochemical behavior of the defective coatings with $85 \mu \mathrm{m}$ thickness}

From the electrochemical tests, the failure process of the defected coating can be more clearly observed. Fig. 13 shows the electrochemical behavior for the two coatings as a function of different immersion times. The fast decrease in the low-frequency impedance (Fig. 13a) and arc (Fig. 13b) for the styrene-acrylic coating indicates fast development of the corrosion reactions in the coating/metal interface. In contrast, the low-frequency impedance value for the terpolymer coating is always maintained around $10^{5}$ $\Omega$ and it decreases very slowly with the immersion time.

For the scratched coatings, the corrosive ions directly contact and react with the exposed metal substrates. Therefore, the circuit model in Fig. 6b is used to fit the initial impedance. With the extension of immersion time, corrosion products are accumulated in the defect, which causes the impedance to change from the two time constants circuit models to three time constants circuit models. At this immersion stage, the circuit model in Fig. 6c.

Poleman $^{32}$ reported that the electric double layer capacitor $\left(C_{\mathrm{dl}}\right)$ and charge transfer resistance $\left(R_{\mathrm{ct}}\right)$ are related to electrochemical reactions of the coating/metal interface. These reactions will cause coating failure and peel off in the end. Therefore, $C_{\mathrm{dl}}$ and $R_{\mathrm{ct}}$ are closely related to the peeling of the coating. An increase in $C_{\mathrm{dl}}$ implies an increase in the area of coating/metal disbonding.

$Q_{\mathrm{dl}}$ of the scratched coatings that were immersed in the 3.5 $w t \% \mathrm{NaCl}$ solution at different immersion stages went through the fitting the circuit. As shown in Fig. 14, the peeling process of the styrene-acrylic coating is divided into two stages. In the initial 3 days, the peeling rate was increasing rapidly with the fast development of corrosion reactions. After that, the peeling rate was slowed down because the accumulation of corrosion products. The terpolymer coating exhibited a good wet adhesive force, and no evident peeling trend is illustrated in Fig. 14. The fitting results were also corresponding to the variation in coating morphologies. 

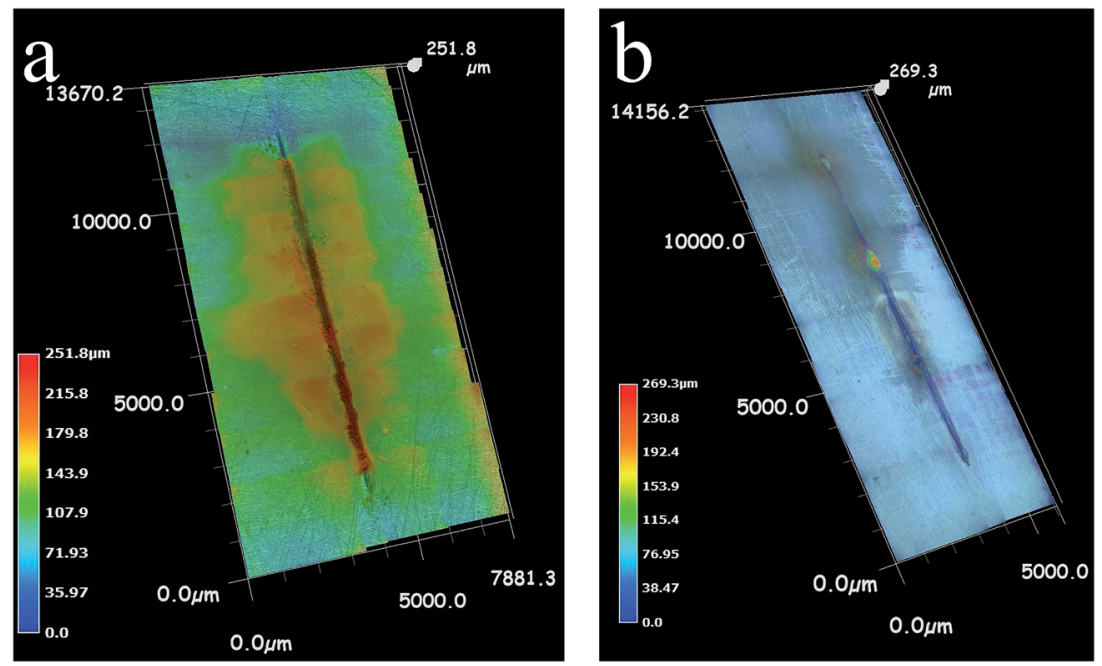

Fig. 12 3D morphology of the two scratched coatings after 8 days of immersion tests, (a) styrene-acrylic coating, (b) terpolymer coating.

Based on the above EIS testing, we use localized electrochemical impedance spectroscopy and wet adhesion testing to further study the failure behavior of the defective coatings.
Fig. 15 presents the variation of the delaminated surface area of the styrene-acrylic coating with defects, measured by LEIS after different immersion times in $3.5 \mathrm{wt} \% \mathrm{NaCl}$ solution. The
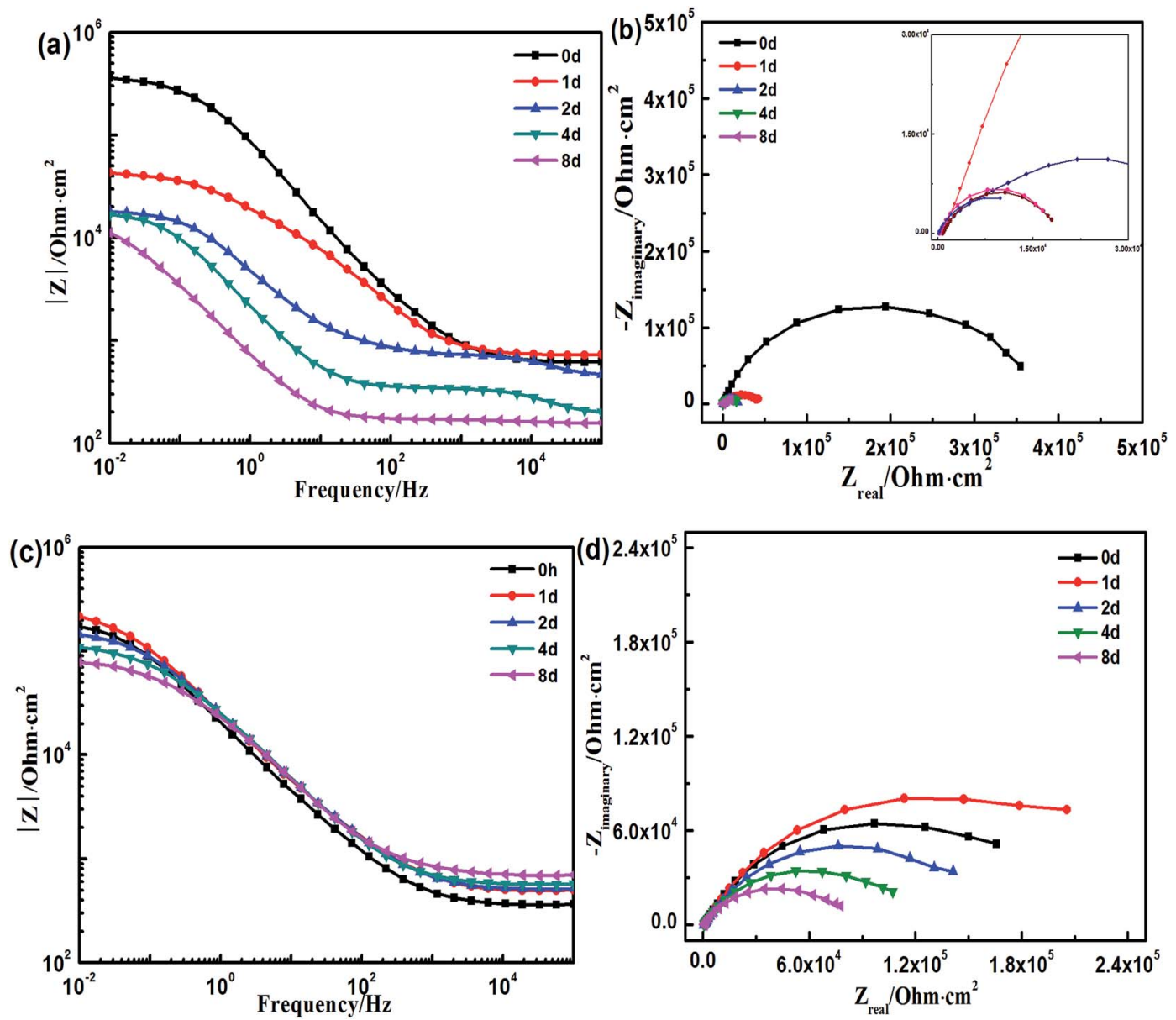

Fig. 13 Electrochemical impedance of the defected coatings (thickness is $85 \mu \mathrm{m}$ ) at different immersion times, (a) and (b) Bode and Nyquist plots of the styrene-acrylic coating, (c) and (d) Bode and Nyquist plots of the terpolymer coating. 


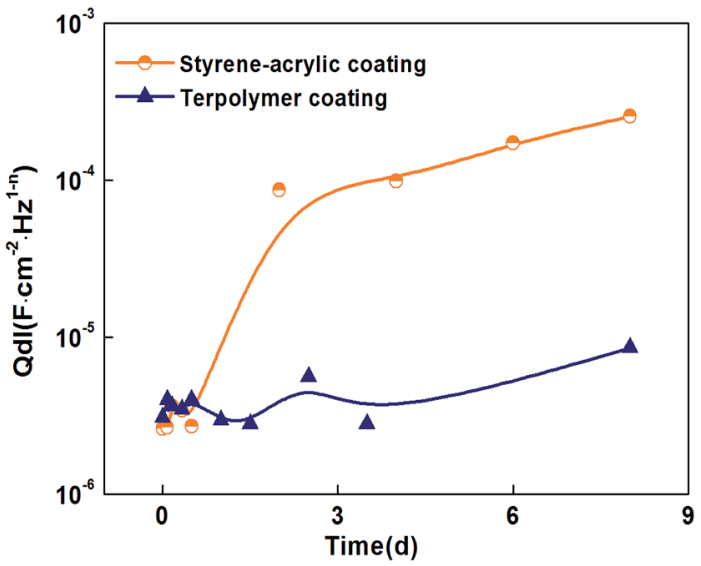

Fig. 14 The double-layer capacitance, $Q_{d l}$, as a function of the immersion time of the defected coatings (thickness is $85 \mu \mathrm{m}$ ) in the different immersion time.

color from blue to red is indicative of an increase. The impedance value at the center of the defect is the least and it decreases because of the corrosion of the metal substrate. Delamination of the coating is indicated by the color of the coating near the defect changes from red to blue and the area expands rapidly.
The results of the LEIS for the styrene-acrylic coating show that the delamination becomes serious after $3 \mathrm{~h}$, and the coating in the testing area also peeled off completely after $6 \mathrm{~h}$.

Fig. 16 presents the LEIS maps obtained for the terpolymer coating with scratch defects at different immersion times in the 3.5 wt $\% \mathrm{NaCl}$ solution. The impedance value at the center of the deflect decreases with the extension of the immersion time, but the value of the coating near the defect declines slowly. This indicates that corrosion of metal substrate in the center of the defect is aggravated with the extension of the immersion time, but the rate of delamination is much lower than the styrene-acrylic coating.

\section{Discussions}

When the coating was thin enough (about $3 \mu \mathrm{m}$ ), infrared waves could traverse through it and reflect the composition of the coating/metal interface. Fig. 17 shows the infrared analysis results of terpolymer and styrene-acrylic resins and coatings in carbon steel substrate. For the terpolymer resin, a new peak in the vicinity of 1740 was formed after curing on carbon steel surface, this may be due to the carbonyl which produced by the reaction between the resin's carboxyl groups and the matrix metal. ${ }^{15}$ For the styrene-acrylic resin, no change was observed in the original position, except that the peak intensity
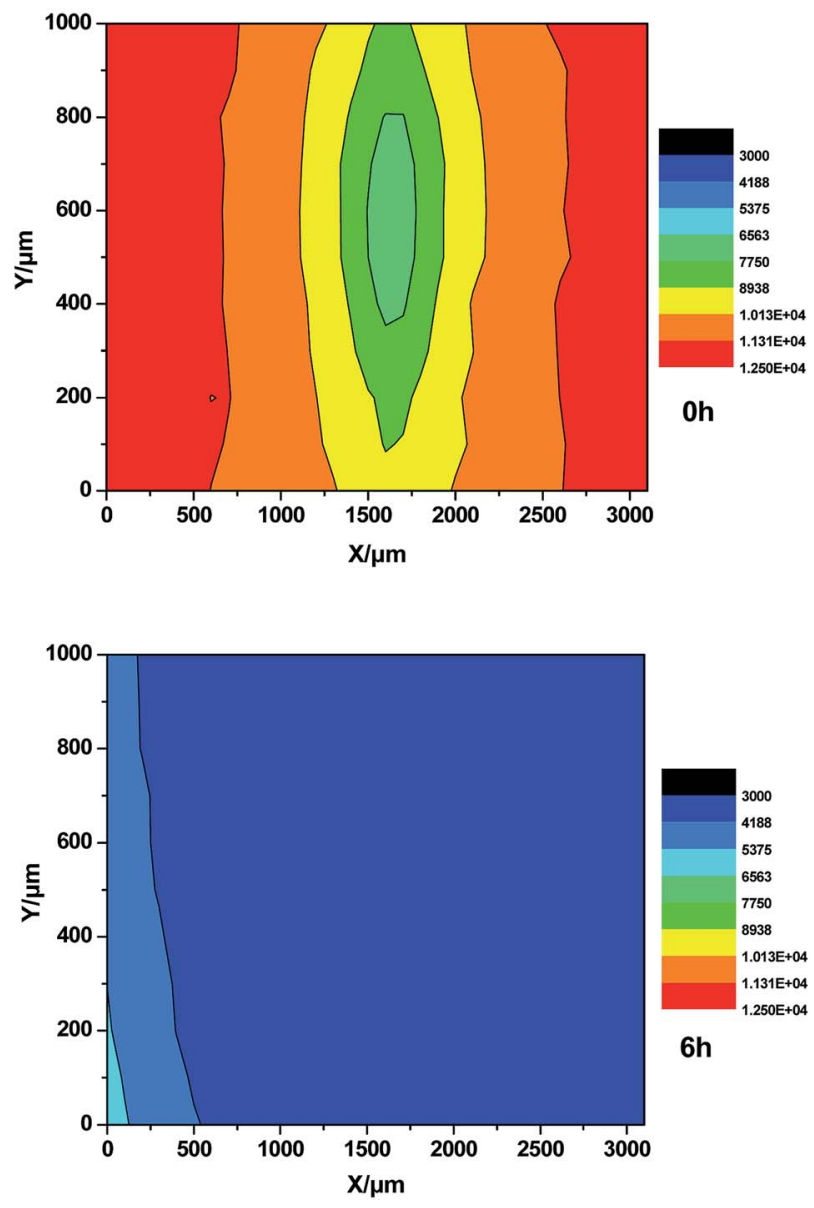

Fig. 15 LEIS of the styrene-acrylic coating with scratch defects immersed in $3.5 \mathrm{wt} \% \mathrm{NaCl}$ solution under different durations.

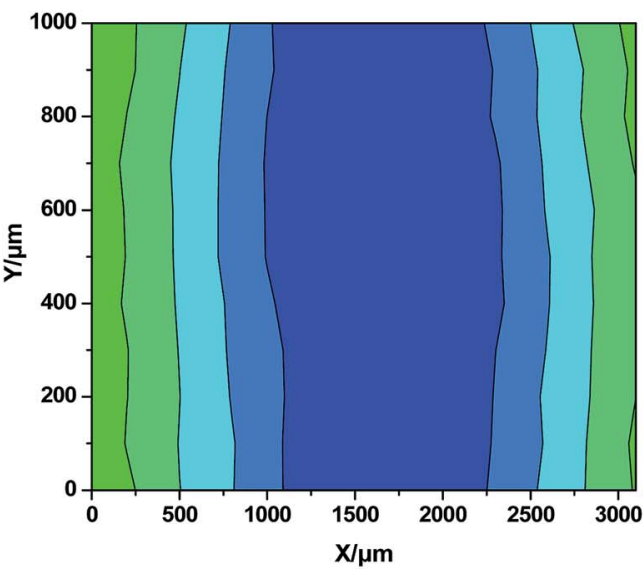

$3 \mathrm{~h}$
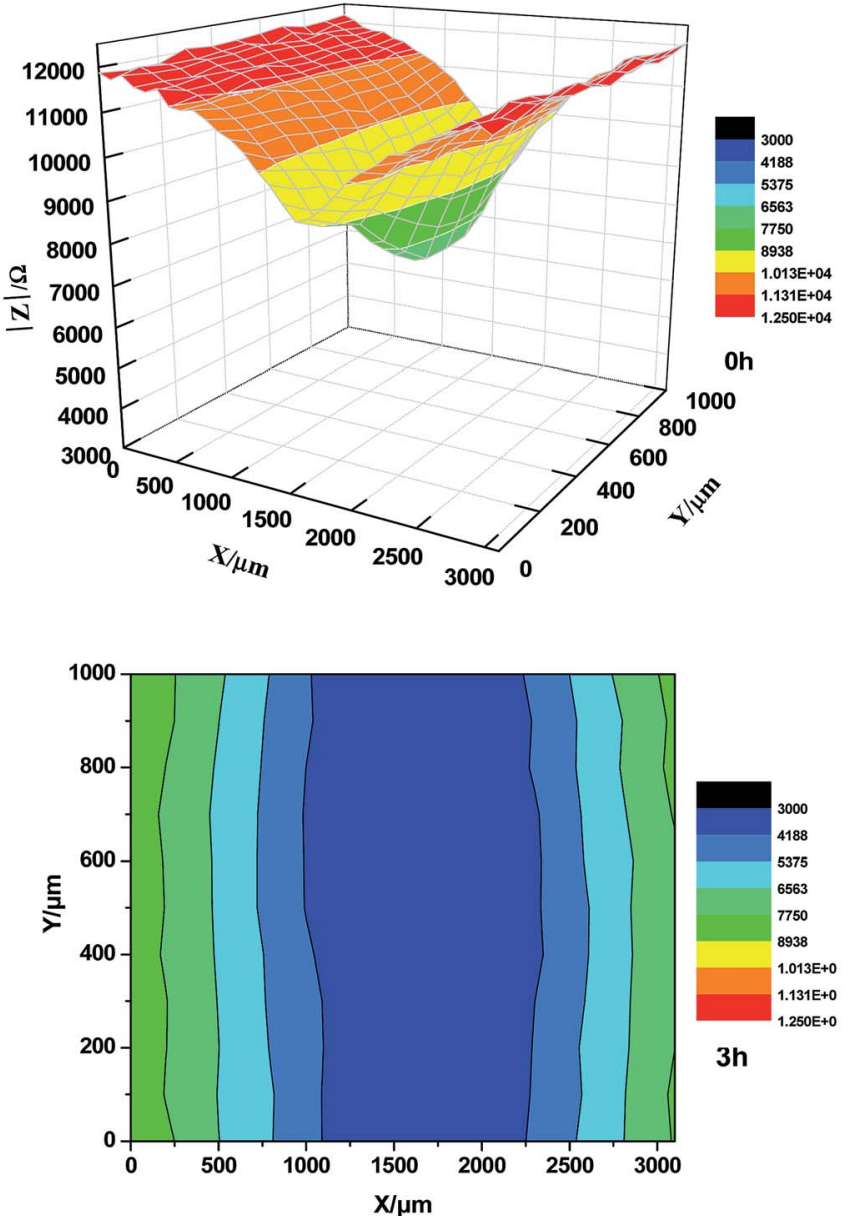

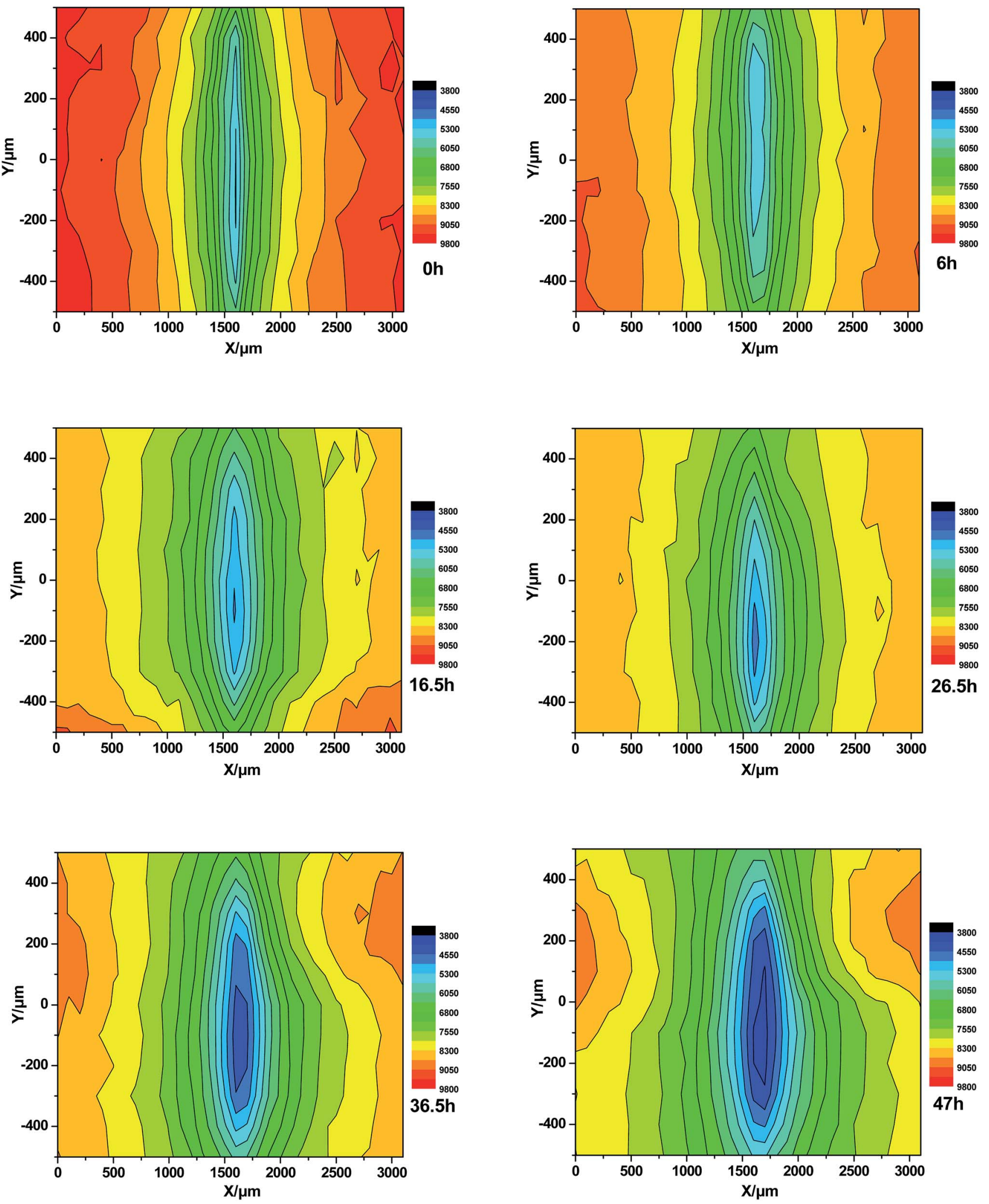

Fig. 16 LEIS of terpolymer coating with scratch defects immersed in $3.5 \mathrm{wt} \% \mathrm{NaCl}$ solution at different immersion times.

increased. In order to further confirm the infrared results, the terpolymer coating was analyzed by secondary ion mass spectrometry (SIMS).
Fig. 18 shows the SIMS results of the terpolymer coating on the carbon steel surface. In SIMS, ionized particles are ejected from the surface by the bombardment of a primary ion beam 

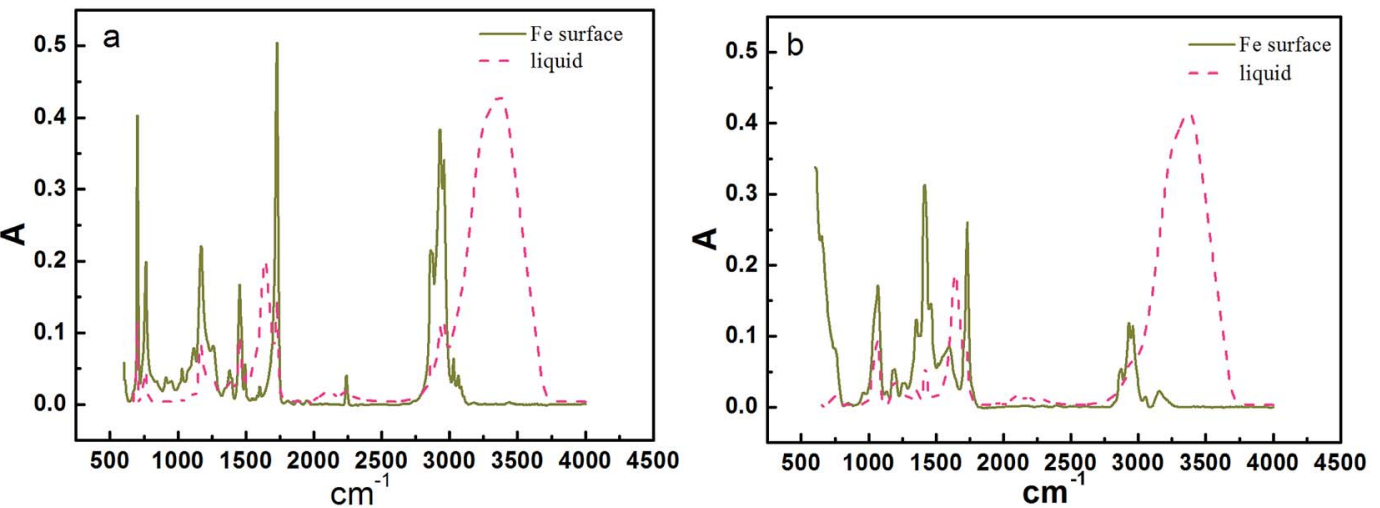

Fig. 17 Infrared results of (a) styrene-acrylic and (b) terpolymer coatings.

$\left(\mathrm{Ar}^{+}, \mathrm{F}^{-}, \mathrm{O}^{2+}, \mathrm{O}^{-}\right.$, and $\left.\mathrm{Cs}^{+}\right)$and then separate according to masses. Both atoms and molecules can be ionized. Thus, details about the chemical state of atoms in the surface, such as bonding, are obtained. In Fig. 18, the peak at $100 \mathrm{~nm}$ implies that COOFe bonding existed on the coating/metal interface, which was the same with the results of IR, the results both showed that there existed a stable bond between the terpolymer coating and metal substrate. However, no bonding occurred between the styrene-acrylic coating and metal substrate.

On the basis of the above-mentioned results, a schematic of the failure mechanisms of the two different intact coatings are shown in Fig. 19. For the styrene-acrylic coating, activities of the molecular chains are weak, and the diffusion of water in the coating is a type of physical mode and inert. In the absence of any damages and defects, the coating is compact, exhibits good water barrier properties, and provides good corrosive resistance. The styrene-acrylic coating is more compact than the terpolymer coating (Fig. 1). Therefore, the $85 \mu \mathrm{m}$ thick styreneacrylic coating continues to behave as a one time constant circuit model after 300 days of immersion in $3.5 \mathrm{wt} \% \mathrm{NaCl}$ solution (Fig. 5a and b). The change in the capacitance of the coating indicates that there is only a single water absorption

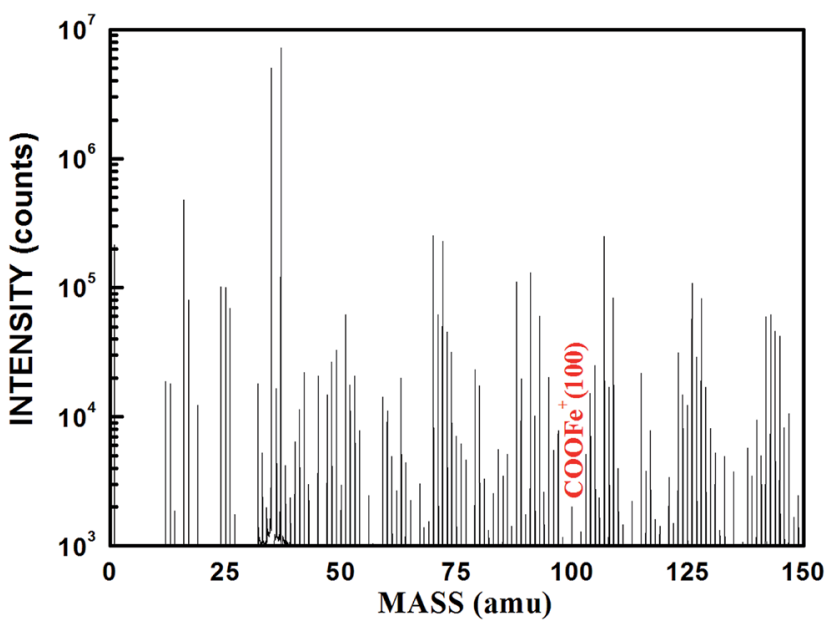

Fig. 18 SIMS result of the interface between the terpolymer coating and metal. process without occurrence of corrosion even after a total immersion of 300 days (Fig. 7). However, when the thickness is lost, the porosity of the coating increases, providing access for water diffusion. When exposed to corrosive media, the corrosion reaction rapidly occurs on the coating/metal interface and expands suddenly, such as in case of the styrene-acrylic coating of $20 \mu \mathrm{m}$ thickness (Fig. 8). The impedance behaves as two time constants circuit model in the initial part of the immersion test for the styrene-acrylic coating. Therefore, the circuit model in Fig. $6 \mathrm{~b}$ is capable for performing the fitting analysis for the styrene-acrylic coating. The $Q_{\mathrm{dl}}$ values of the styrene-acrylic coating also decline rapidly (Fig. 10). These trends illustrate that the styrene-acrylic coating has an excellent barrier property, but also exhibits weak adhesion to the metal substrate, so that the corrosion will expand quickly when the corrosive media approach the metal substrate (Fig. 19a). For the terpolymer coating, the diffusion of water in the coating is active, and it is easy for water to reach the interface between the coating and substrate. However, owing to the tight bonding (COOFe) between the coating and substrate in the terpolymer coating, ${ }^{33}$ the reaction zone is limited to a small range. Therefore, even after 300 days of immersion in $3.5 \mathrm{wt} \% \mathrm{NaCl}$ solution, the terpolymer coating did not peel off from the substrate and only small blisters are formed (Fig. 4). Furthermore, the impedance of the coating maintains two time constants circuit model for more than 150 days (Fig. $5 \mathrm{c}$ and d). With the thickness

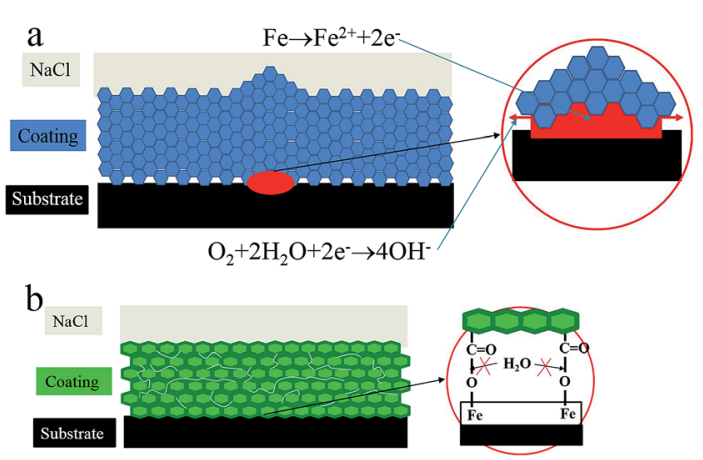

Fig. 19 Schematic of the failure mechanisms of the styrene-acrylic (a) and terpolymer (b) coating/metal interface. 
decreasing, the diffusion of water in the coating becomes more obvious, but the barrier performance becomes weak. At the start of the immersion, impedance of both the coatings had two time constants (Fig. 9). The protection provided by the coating therefore, mainly depends on the wet adhesion. The terpolymer coating has a more reliable bonding in the coating/metal interface compared with the styrene-acrylic coating (Fig. 2 and 3). The corrosion on the interface of the coating and metal will be inhibited for the terpolymer coating, and the corrosion will only take place in a relatively small area as shown in Fig. 6c. Therefore, the model in Fig. 19b was used to fit this process. The anticorrosive performance of the terpolymer coating is better than the styrene-acrylic coating with $20 \mu \mathrm{m}$ thickness as shown in Fig. 10.

For the coating with defects, the corrosion failure process is the delamination from the defects. In general,

(1) The bare metal in the defect is directly in contact with the corrosive media (water, oxygen, and chloride ion) and corrodes rapidly. Corrosion products are formed at the defect and spread out around it as Fig. 11. In the presence of chloride, fairly soluble ferrous chloride hydrate or hydroxy chlorides are formed (rusty layer). The transformation of these corrosion products to yield insoluble oxides, e.g. $\mathrm{Fe}_{2} \mathrm{O}_{3}$, by hydrolysis and oxidation (black layer) leads to the release of chloride anions that can again participate in producing soluble primary corrosion products, thus, enhancing the action of the local corrosion elements auto-catalytically.

(2) Oxygen, which diffuses through the intact coating near the defect, is reduced to $\mathrm{OH}^{-}$by the electron that is produced by the corrosion of the bare metal. ${ }^{34}$ Therefore, the $\mathrm{pH}$ near the defect increases and a cathode is formed. Simultaneously, the defect becomes the anode.

(3) The anodic zones advance owing to the formation of the corrosion products, increasing the area of oxygen reduction and thus, propagating the delamination under the coating as shown in Fig. 12.

Development of this process requires the transverse diffusion of cations on the interface between the coating and metal. There will be a potential difference $(\Delta \varphi)^{35}$ between the isolated sites ("defect and intact interface") as a driving force before any ionic conductivity will link these two sites during delamination as in Fig. 20. At the same time, the front of the delamination will be inhibited by the adhesion of the coating.

Fig. 20 shows the failure model of the two coatings with defects. Because the bonding between the styrene-acrylic coating and metal is mainly controlled by the mechanical bonding, thus, wet adhesion is weak. Corrosion and delamination spread out around the defect quickly. Although the barrier of the terpolymer coating is weak, the excellent wet adhesion will inhibit the transverse diffusion of cations on the interface between the coating and metal. The development of the delamination is controlled.

Therefore, the adhesion, particularly wet adhesion, is essential to the protective properties of the coating. Wet adhesion will impede the communication of the local anode and local cathode by the electrolyte, to prevent further development of the corrosion. Yamabe ${ }^{15}$ reported that the acrylic acid can
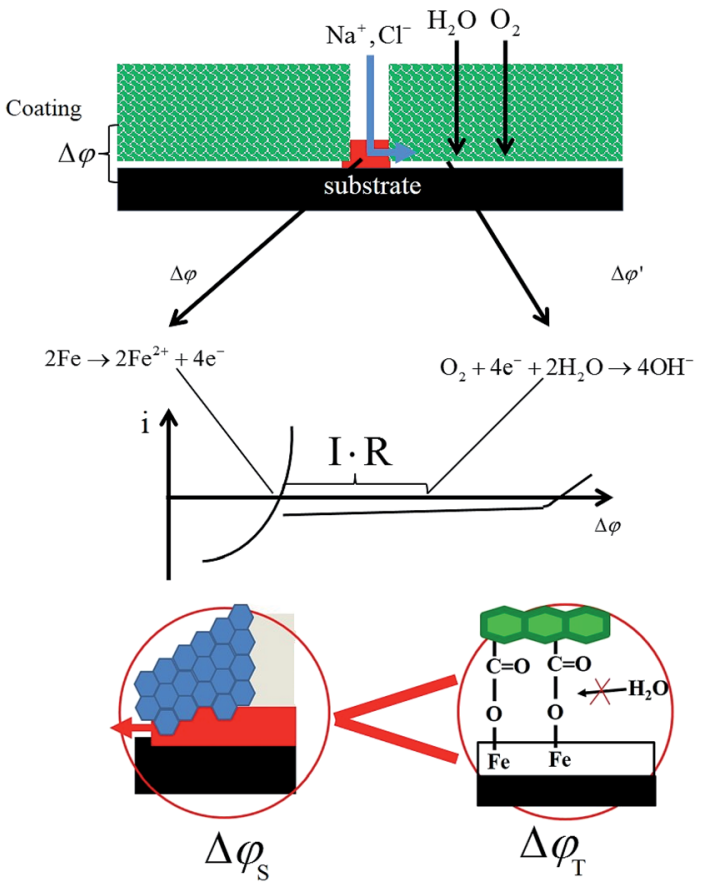

Fig. 20 Schematic of the failure mechanism of the coating with scratch defects at the coating/metal interface.

form a stable chemical bond on the Fe surface on the basis of theoretical calculations. However, because of the different chemical components, the number and degree of ionization for acrylic acid monomers, and other impacts, it is hard to ensure the chemical bonding in the coating/metal interface. Although both coatings contain acrylic acid monomers, the terpolymer coating shows better wet adhesive force compared with the styrene-acrylic coating. This may be attributed to the much stronger bonding of COOFe formed in the coating/metal interface for the terpolymer coating, which results from the ionization of the carboxylic acid in the coating latex. The $\mathrm{pH}$ of the styrene-acrylic coating is approximately 7 , and of the terpolymer coating is approximately $1-2$. The low $\mathrm{pH}$ condition resulted from high ionization of the carboxylic acid. The ionized carboxylic acid then bonds with the Fe ions and forms the bonds of the type COOFe in the coating/metal interface. The chemical bonding cannot promote the mechanical cohesive and provide higher adhesive force like the styrene-acrylic coating, this is why the styrene-acrylic coating has higher initial adhesive force than terpolymer coating, the chemical bonding can provide a much more reliable way to protect the metal, and this is not easy to be broken by the corrosive ions as Fig. 11 and 13. Therefore, the terpolymer coating can offer a better protection to the metallic substrates than the styrene-acrylic coating under a corrosive environment $(\Delta \varphi T>\Delta \varphi S)$. Fig. 14 indicates that the delamination of the terpolymer coating was much less than of the styrene-acrylic coating. Fig. 15 and 16 also demonstrate that the initiation of delamination for the terpolymer coating is harder than for the styrene-acrylic coating, and there is need for a greater driving force for the terpolymer coating to delaminate. 


\section{Conclusions}

In this work, the barrier property and adhesion of two types of waterborne acrylic latex coatings on carbon steel were investigated via EIS measurements over a long period of exposure and via LEIS over a short period of exposure in $3.5 \mathrm{wt} \% \mathrm{NaCl}$ solution. Based on the morphology and electrochemical studies of intact and defective coatings that were $85 \mu \mathrm{m}$ thick, the key roles played by the barrier property and adhesion of the coatings in corrosion protection were directly demonstrated. Among the intact coatings, the styrene-acrylic coating with a relative high level of hydrophobicity and $T_{\mathrm{g}}$ value showed a better barrier property compared with the terpolymer coating. In case of defective coatings, all the different results proved that the terpolymer coating with the better wet adhesion exhibited a better anticorrosion performance compared with the styreneacrylic coating. The main function of wet adhesion in corrosion protection was also confirmed by performing tests with thinner intact coatings of $20 \mu \mathrm{m}$ thickness. In general, we found that a good barrier property can effectively repel the corrosive species and slow down the penetration rate of the corrosive medium, while a tight adhesion force between the coating and metal interface can significantly hinder the lateral diffusion of the corrosive ions and resist the occurrence of corrosion reactions.

\section{Acknowledgements}

The authors wish to acknowledgement the financial support from National Basic Research Program of China (973 Program) (No. 2014CB643300) and National Natural Science Foundation of China (Grant No. 51371036).

\section{References}

1 X. Li, D. Zhang, Z. Liu, Z. Li and C. Du, Nature, 2015, 527, 441-442.

2 H. Vakili, B. Ramezanzadeh and R. Amini, Corros. Sci., 2015, 94, 466-475.

3 M. S. Ghaffari, R. Naderi and M. Sayehbani, Prog. Org. Coat., 2015, 86, 117-124.

4 M. F. Montemor, Surf. Coat. Technol., 2014, 258, 17-37.

5 S. Jafarzadeh, P. M. Claesson, J. Pan and E. Thormann, Langmuir, 2014, 30, 1045-1054.

6 W. van Zoelen, H. G. Buss, N. C. Ellebracht, N. A. Lynd, D. A. Fischer, J. Finlay, S. Hill, M. E. Callow, J. A. Callow, E. J. Kramer, R. N. Zuckermann and R. A. Segalman, ACS Macro Lett., 2014, 3, 364-368.

7 J. Sun, L. Wang, K. Hu, J. L. Song and X. Liu, Micro Nano Lett., 2015, 10, 88-92.

8 M. Liu, X. H. Mao, H. Zhu, A. Lin and D. H. Wang, Corros. Sci., 2013, 75, 106-113.

9 C. Motte, M. Poelman, A. Roobroeck, M. Fedel, F. Deflorian and M. G. Olivier, Prog. Org. Coat., 2012, 74, 326-333.
10 J. B. Bajat and O. Dedic, J. Adhes. Sci. Technol., 2007, 21, 819831.

11 Y. Gonzalez-Garcia, S. Gonzalez and R. M. Souto, Corros. Sci., 2007, 49, 3514-3526.

12 M. S. Islam, L. Tong and P. J. Falzon, Int. J. Adhes. Adhes., 2014, 51, 32-41.

13 A. Varesano, F. Rombaldoni, C. Tonetti, S. Di Mauro and G. Mazzuchetti, J. Appl. Polym. Sci., 2014, 131(2), 39766.

14 M. R. Chashmejahanbin, H. Daemi, M. Barikani and A. Salimi, Appl. Surf. Sci., 2014, 317, 688-695.

15 H. Yamabe, Prog. Org. Coat., 1996, 28, 9-15.

16 P. A. Sørensen, K. Dam-Johansen, C. E. Weinell and S. Kiil, Prog. Org. Coat., 2010, 68, 283-292.

17 J. Friedrich, G. Kuhn, R. Mix, A. Fritz and A. Schonhals, J. Adhes. Sci. Technol., 2003, 17, 1591-1617.

18 S. Morsch, S. Lyon, P. Greensmith, S. D. Smith and S. R. Gibbon, Prog. Org. Coat., 2015, 78, 293-299.

19 L. G. Ecco, J. Li, M. Fedel, F. Deflorian and J. Pan, Prog. Org. Coat., 2014, 77, 600-608.

20 A. Ghanbari and M. M. Attar, J. Ind. Eng. Chem., 2015, 23, 145-153.

21 D. Zhang, H. Qian, L. Wang and X. Li, Corros. Sci., 2015, 103, 230-241.

22 J. Li, L. Ecco, G. Delmas, N. Whitehouse, P. Collins, F. Deflorian and J. S. Pan, J. Electrochem. Soc., 2015, 162, C55-C63.

23 H. B. Li, Z. Y. Fu, L. Yang, C. Yan, L. M. Chen, J. H. Huang and Y. N. Liu, RSC Adv., 2015, 5, 26616-26624.

24 N. Kessel, D. R. Illsley and J. L. Keddie, J. Coat. Technol. Res., 2008, 5, 285-297.

25 M. J. Deriss and O. J. Karlsson, Surf. Coat. Int., Part B, 2005, 88, 251-256.

$26 \mathrm{~J}$. Keddie and A. F. Routh, Fundamentals of latex film formation: processes and properties, Springer Science \& Business Media, 2010.

27 M. A. Winnik, J. Coat. Technol., 2002, 74, 49-63.

28 J. W. Taylor and M. A. Winnik, JCT Res., 2004, 1, 163-190.

29 J. Li, L. Ecco, G. Delmas, N. Whitehouse, P. Collins, F. Deflorian and J. Pan, J. Electrochem. Soc., 2015, 162, C55-C63.

30 J. Valli, J. Vac. Sci. Technol., A, 1986, 4, 3007-3014.

31 X. Sun, Z. Jiang, S. Xin and Z. Yao, Thin Solid Films, 2005, 471, 194-199.

32 M. Poelman, M. G. Olivier, N. Gayarre and J. P. Petitjean, Prog. Org. Coat., 2005, 54, 55-62.

33 H. Wan, D. Song, X. Li, D. Zhang, J. Gao and C. Du, Materials, 2017, 10(4), 397.

34 K. Bartoň, S. Bartoňová and E. Beranek, Mater. Corros., 1974, 25, 659-663.

35 A. Leng, H. Streckel and M. Stratmann, Corros. Sci., 1998, 41, 547-578. 